\title{
Why publish?
}

\author{
Jamie Trapp
}

Published online: 29 November 2011

(C) Australasian College of Physical Scientists and Engineers in Medicine 2011

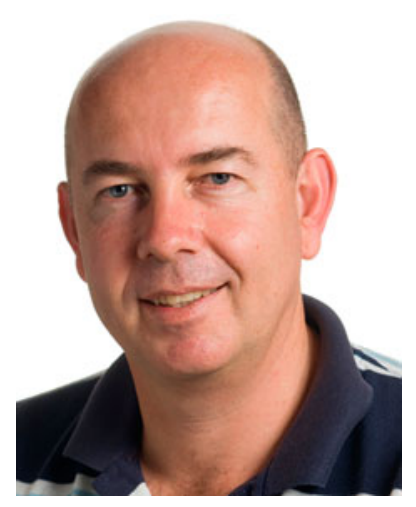

Anybody who has attempted to publish some aspect of their work in an academic journal will know that it isn't as easy as it may seem. The amount of preparation required of a manuscript can be quite daunting. Besides actually writing the manuscript, the authors are faced with a number of technical requirements. Each journal has their own formatting requirements, relating not only to section headings and text layout, but also to very small details such as placement of commas in reference lists. Then, if presenting data in the form of figures, this must be formatted so that it can be understood by the readership, and most journals still require that the data be in a format which can be read when printed in black-and-white. Most daunting (and important) of all, for the article to be scientifically valid it must be absolutely true in the representation of the work reported (i.e. all data must be shown unless a strong justification exists for removing data points), and this might cause angst in the mind of the authors when the results

J. Trapp $(\square)$

School of Physical and Chemical Sciences, Queensland University of Technology, Brisbane, QLD 4001, Australia e-mail: j.trapp@qut.edu.au aren't clear or possibly contradict the expected or desired result.

As somebody who has supervised several postgraduate students writing their first paper, the most difficult message to get through to the student is that a manuscript must be of a 10/10 standard before being submitted, and even then expect it to be torn to shreds by some reviewers in ways you can't even conceive. In fact, I recall that as a postgraduate student my first journal submission went through 24 drafts before my supervisors would allow me to submit it - and even after all of that 'perfecting' the eventual reviews came back with over 60 changes to be made. I now regularly see the same looks from students who I supervise, as the looks I must have been giving my supervisors back in that distant past.

After undergoing the rigours of completing the work and then writing the manuscript, authors submit it to a journal and usually nothing happens for quite a while. Eventually, reviewer reports will arrive which may be supportive, may be critical (and occasionally insulting), or worst, after all the work the article is rejected with some harsh reviewer comments added just to rub salt into the wound.

The question then is, why would you bother attempting to publish your work in a journal? There are two answers to this question, the first is that the process actually does get easier the more you publish, and the second is that the benefits of publishing are greater than the effort required and the risk of a rejection. Those benefits will be discussed here.

1. You did the work, why not get the recognition? Despite the doom and gloom I outlined above, if you've gone to the effort of doing some original hard work, it's usually a relatively small amount of effort in writing it up as a manuscript once you've got the data analysed. 
Whether the work is experimental, simulations of something new, solving a problem in your local centre, or purely theoretical, why not claim it as your own? Even if there isn't a sufficient amount of work for a full journal paper, most scientific journals have the capacity to publish smaller works as technical notes, scientific notes, letters to the editor etc.

2. Others might benefit from your findings. Even if you're too modest to publish for personal recognition, publishing your work might help others and it leaves a permanent record of the work which has been done. This is particularly important in clinical settings where the sharing of data between centres with similar equipment benefits the patient. Sometimes even failed experiments that have been published have led to greater things (physicists only need to recall their undergraduate teachings of the Michelson-Morely 'failed' experiment and how this supported the notion of the constancy of the speed of light in a vacuum, and thus supporting special relativity).

3. It's good for the CV. I can hear the arguments against this statement already- "But my work is purely clinical/industrial, publications don't matter for me". The simple fact is that it does matter and publishing your work will build your reputation. If two people with equal clinical expertise and experience apply for a job, all things being equal, the candidate with the stronger reputation has a better chance of success. In addition, publishing papers demonstrates your ability to communicate effectively.
4. It helps if you apply for project funding. Whether you apply for large competitive grants or small amounts of money from local sources for small projects, a history of publication shows that you're capable of getting meaningful outcomes from a project. For those vested with the responsibility of handing out the cash, this is an important consideration.

5. For those undertaking a PhD, it matters greatly. Good scientific work alone is not sufficient for a $\mathrm{PhD}$, these degrees are awarded on originality of work. Publication confirms originality and makes it easy for examiners to recommend passing the degree. I have seen groundbreaking work completed in the early stages of a candidates part-time $\mathrm{PhD}$, only to have it deemed 'not original' in the final thesis because the work was not published early and it had become outdated by the time the thesis was submitted.

An aside to the last point; if you are in the habit of publishing your work and don't have a PhD, it's worth considering enrolling. Most universities will look favourably upon an applicant who is already actively publishing and many have the capacity to waive fees under certain conditions.

In conclusion, publishing your work in a peer-reviewed journal may be a daunting prospect and a little time consuming, but the process gets easier the more it's done, and there are significant advantages to be had. As a senior colleague of mine with over 900 publications says, "You might do the best science in the world, but nobody will know or benefit if you don't tell anybody about it". 